\title{
A Comparative Study of Inter-firm Transactional Relationship between Kyohokai and Yokokai
}

\author{
Takao Ito* \\ Graduate School of Engineering, Hiroshima University, Higashi-Hiroshima, 739-8527 Japan \\ Makoto Sakamoto, Satoshi Ikeda \\ Dept. of Computer Science and Systems Engineering, University of Miyazaki, 889-2192 Japan \\ Rajiv Mehta \\ School of Management, New Jersey Institute of Technology, 07102-1982 U.S.A \\ Yasuo Uchida \\ Dept. of Business Administration, Ube National College of Technology, Yamaguchi, 755-8555 Japan \\ *Corresponding author, E-mail: itotakao@hiroshima-u.ac.jp \\ Tel: +81-985-58-7392, Fax: +81-985-58-7392
}

\begin{abstract}
Although two major Japanese manufacturers, Toyota and Mazda, compete in the automotive market, their corporate performance, respectively, is different because the internal resources and the way they coordinate interrelationships among their network partners is known to be divergent. Both these two companies have their own collaborating organizations, Kyohokai for Toyota and Yokokai for Mazda. Kyohokai, in contrast to Yokokai, is a central-oriented organization with strong interactive cooperation among network partners. Consistent with the stream of research on the coordination of internal resources and external inter-firm relationships, the purpose of this research is to identify and contrast the best practices of Toyota to Mazda using a comparative approach. This paper reviews relevant lliterature on network organizations to focus on the differences between Kyohokai and Yokokai. Specifically, it makes a contribution by proposing a new perspective to identify the determinants of corporate performance and clarify the difference among the external inter-firm's relationships between Kyohokai and Yokokai, thus ascertaining the rational structure of network organizations.
\end{abstract}

Keywords: out-influence, in-degree, sales, the OIS model, Kyohokai, Yokokai, Keiretsu.

\section{Introduction}

Although two major Japanese manufacturers, Toyota and Mazda, compete in the automotive market, their corporate performance, respectively, is different because the internal resources and the way they coordinate inter-relationships among their network partners is known to be divergent. Both of these two companies have their own collaborating organizations, Kyohokai for Toyota and Yokokai for Mazda. Kyohokai, in contrast to Yokokai, is a central-oriented organization with strong interactive cooperation among network partners. Consistent with the stream of research on the coordination of internal resources and external inter-firm relationships, the purpose of this research is to identify and contrast the best practices of Toyota to 
Mazda using a comparative approach. This research makes a contribution to the literature by proposing a new perspective to identify the determinants of corporate performance and clarify the difference among the external inter-firm's relationships between Kyohokai and Yokokai, thus ascertaining the rational structure of network organizations.

This paper is organized as follows. In Section 2, we briefly review some relevant researches of quantitative approaches of Keiretsu. Section 3 introduces the OIS spatial model. Section 4 shows the results, and discusses the implications of the results. Finally, Section 5 provides conclusions and summarizes this study.

\section{Background}

Relationship, one of the important factors in structural analysis, has basically been analyzed using quantitative and qualitative approaches. Nowadays, quantitative approach is widely used due to the development of computer technology and mathematical theories. Quantitative approaches are required to ascertain the structure of any given network. Inter-organizational relationships in the Keiretsu have been analyzed with quantitative analysis tools such as CONCOR and other statistical methods [1]. Furthermore, Fukuoka et al. reported a new finding in relationships among member firms in Nissan's Keiretsu using transactions and cross shareholdings [2]. Recently Ito et al. begin to apply graph theory to network organization analysis, and clarifies some characteristics such as centrality, size of network [3-9]. A comparative study is one of the useful tools to uncover the common characteristics and differences in successful cases. After reviewing the relevant literature of network organizations, we found that only a few comparative studies have been published. Therefore, we focus on the common successful factors and differences between Kyohokai and Yokokai in this paper.

\section{Method}

In order to identify the determinants of supplier revenues, we calculated the network indices including influence, degree, effective size, efficiency, constrain, hierarchy, and density. We found that only influence and degree are significant. Thus, we analyzed the relationship between two significant explanatory variables: out-influence and in-degree, and explained variable: sales, which is one measure of corporate performance. Therefore, we propose a new approach, known as the OIS spatial model, to identify the common factors and also to illustrate the differences between Kyohokai and Yokokai.

\subsection{Outline of the OIS model}

Generally, a graph consists of a set of nodes and a set of arcs. Two nodes are connected if a path between these two nodes. Path is one of the important concepts in graph theory. According to graph theory, a path is a sequence of nodes such that the nodes and the arc are adjacent. A walk is a sequence of nodes and arcs such that the nodes and arcs are adjacent. The difference between path and walk is that a path is a walk that does not include any node twice, except that it its first node might be the same as its last. For digraphs, walks can travel arcs only in the direction of the arrows.

In general, influence means one kind of powers to affect persons or events, or causing something without any direct or apparent effort. Influence reflects the power to influence or have an impact on other member firms directly and indirectly in a network. Consequently, influence will be divided into two parts: direct influence and indirect influence in a network. Suppose that A is the matrix of the direct network, and An means the indirect influence from one node to another node by $n$ steps. Then, influence is calculated as follows.

$$
\begin{aligned}
& T=A+R=A+A^{2}+A^{3}+\cdots+A^{n} \\
& =A(I-A)^{-1}
\end{aligned}
$$

where

T: Total influence;

A: direct influence;

$\mathrm{R}$ : indirect influence;

I: Identity matrix.

Because transaction network is asymmetric, influence will be divided into two parts: out-influence and ininfluence.

An integral index known as centrality has many facets that include degree, closeness, and betweenness. Degree expresses a firm's potential communication activity. In cross shareholding network, degree includes two categories: in-degree and out-degree, because cross shareholding networks are considered to be asymmetric organizations. In-degree refers to a firm accept investment from other member firms, whereas out- 
degree reflects a firm that only buy stocks of other firms within the network. Degree is calculated as below.

$C_{D}\left(p_{k}\right)=\sum_{i=1}^{n} a\left(p_{i}, p_{k}\right)$

where

$\mathrm{a}\left(\mathrm{p}_{\mathrm{i}}, \mathrm{p}_{\mathrm{k}}\right)=1$; if and only if $\mathrm{p}_{\mathrm{i}}$ and $\mathrm{p}_{\mathrm{k}}$ are connected by a line

$\mathrm{a}(\mathrm{pi}, \mathrm{pk})=0$; otherwise

Like influence, degree also will be divided into outdegree and in-degree. In this paper, percent data of inter-firm's transactions are collected from Yokokai.

\subsection{Data collection}

In order to ascertain the relationship between network indices and corporate performance, transaction data in the keiretsu of Kyohokai and Yokokai have been drawn from personal interviews as well as the publications of the Japan Auto Parts Industries Association and Automotive Parts Publishing Company [10].

In 2002, 209 parts suppliers, and 11 carmakers are included in Kyohokai. A singleton can be found in any network. Moreover, a singleton is defined as the node exists independently, without any relationship with other nodes in this paper. Therefore, a singleton is an isolated node in a given network generally. In Kyohokai, 90 singletons included. The detailed information of the numbers of parts-supplies, and carmakers in Kyohokai and Yokokai in 2002 are shown

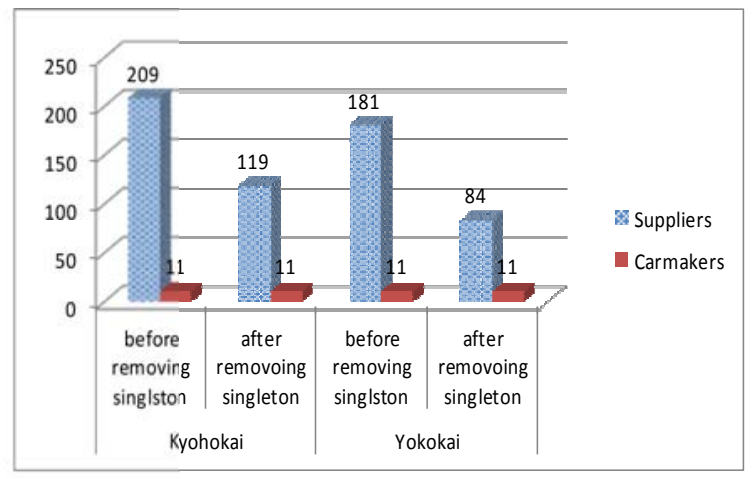

in Fig. 1.

Fig. 1 Numbers of parts-suppliers and carmakers in Kyohokai and Yokokai in 2002
The transactional relationships among the companies were identified through graph modeling. A tie shows the percentage of the transaction between each pair of firms. We collected directed and weighted data to measure out-influence and in-degree of each firm. The transactional network of inter-firm relationships in

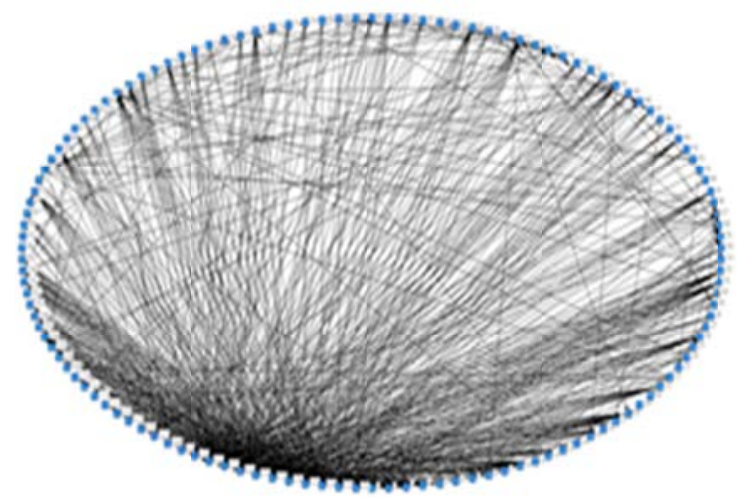

Kyohokai and Yokokai could be shown as Fig. 2 and 3 respectively.

Fig. 2 Transactional network in 2002 in Kyohokai

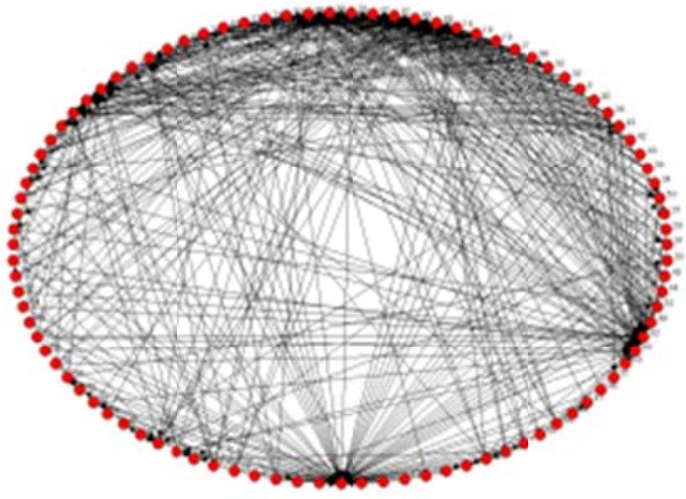

Fig. 3 Transactional network in 2002 in Yokokai

\section{Results and discussions}

\subsection{Central analysis}

The overall centrality of Kyohokai and Yokokai is calculated as follows.

Table 1 Out-degree and in-degree of Kyohokai and Yokokai

\begin{tabular}{|l|r|r|}
\hline & \multicolumn{1}{|c|}{ Out-degree } & \multicolumn{1}{c|}{ In-degree } \\
\hline Kyohokai (Toyota) & $0.341 \%$ & $23.326 \%$ \\
\hline Yokokai (Mazda) & $49.915 \%$ & $1005.184 \%$ \\
\hline
\end{tabular}


Form Table1, it is evident that out-degree and in-degree of Yokokai are larger than of Kyohokai. High centrality means the suppliers purchase their parts from a couple of specific companies. It also means that compared with Yokokai, the companies in Kyohokai have more chances to purchase their parts. This could possibly be the main reason why Kyohokai's firm is more efficient. Consequently, the hypothesis that "the lower the centrality, the higher the performance" holds.

\subsection{Determinants of sales}

We calculated partial correlation coefficient of the seven indices in multiple regression models, and found effective size, density and other 3 indices are not significant. Thus, we removed those 5 variables and reanalyzed the regression model. The results are displayed in Table 2.

Table 2 Results of the variance analysis

\begin{tabular}{|l|c|c|c|c|}
\hline & $\begin{array}{c}\text { Sum of } \\
\text { Squares }\end{array}$ & $\begin{array}{c}\text { Degree } \\
\text { of } \\
\text { Freedom }\end{array}$ & $\begin{array}{c}\text { Mean } \\
\text { Square }\end{array}$ & F Test \\
\hline Total & $3.16 \mathrm{E}+13$ & 81 & & 12.722 \\
\hline Regression & $7.70 \mathrm{E}+12$ & 2 & $3.85 \mathrm{E}+12$ & Prob. \\
\hline Residual & $2.39 \mathrm{E}+13$ & 79 & $3.02 \mathrm{E}+11$ & 0.000 \\
\hline
\end{tabular}

Coefficient of determination: 0.24361

Multiple correlation coefficient: 0.493561

Adjusted R-square: 0.47378

AIC: $2,415.89$

DW ratio: 2.1997

From Table 2, the coefficient of determination is 0.243610 , and DW ratio is 2.1997 . The probability is 0.000 . Therefore, the regression model is significant. The estimated regression coefficients are shown in Table 3.

Table 3 Estimation of regression coefficients

\begin{tabular}{|l|r|r|r|}
\hline & \multicolumn{1}{|c|}{$\begin{array}{c}\text { Out- } \\
\text { Influence }\end{array}$} & In-Degree & Intercept \\
\hline $\begin{array}{l}\text { Partial } \\
\text { regression } \\
\text { coefficient }\end{array}$ & $-3.550 \mathrm{E}+5$ & $6.489 \mathrm{E}+3$ & $4.45187 \mathrm{E}+5$ \\
\hline $\begin{array}{l}\text { Standard } \\
\text { coefficient }\end{array}$ & -0.1697 & 0.4672 & 0.000 \\
\hline T value & -1.7337 & 4.7736 & 2.557 \\
\hline $\begin{array}{l}\text { Degree of } \\
\text { Freedom }\end{array}$ & 79 & 79 & 79 \\
\hline Prob. & 0.0869 & 0.000 & 0.0125 \\
\hline Correlation & -0.1595 & 0.4635 & \\
\hline
\end{tabular}

\begin{tabular}{|l|l|l|l|}
\hline coefficient & & & \\
\hline $\begin{array}{l}\text { Partial } \\
\text { correlation } \\
\text { coefficient }\end{array}$ & -0.0971 & 0.4732 & \\
\hline
\end{tabular}

Based upon Tables 3, out-influence, and in-degree are significant. Out-influence is negative, and in-degree is positive. Out-influence is an index of the structural position of selling its parts, and in-degree an index of purchasing parts from other firms, then the hypothesis of "more purchasing power is associated with higher performance" is upheld.

Basically, high purchasing power means a specific firm is highly capable of producing and selling component parts.

\section{Conclusion and future works}

In this paper, the new approach of OIS model was proposed. This investigation revealed that (1) "lower centrality, higher performance" linkage holds. (2) Outinfluence has a negative impact on sales while in-degree has a positive impact on sales. However, additional research is suggested to develop the theory and knowledge base on rational relationship with other parts suppliers. For instance, it is necessary to clarify the individual firm's position in transactional network to improve its efficiency. The linkage between structural position of each individual firm and their performance is also advocated.

Acknowledgment: This research was partially supported by the Japan Society for the Promotion of Science, Grant-in-Aid for Scientific Research (C) 24510217.

\section{References}

1. Lincoln R. L. and Gerlach M.L. (2004) Japan's Network Economy Structure, Persistence, and Change, Cambridge University Press

2. Fukuoka S., Ito T., Passerini K. and Sakamoto M. (2006) An Analysis between Transaction and Cross Shareholdings in the Keiretsu of Nissan, Managing Information in the Digital Economy Issues \& Solutions, 163-169, IBIMA International Conference, Bonn Germany

3. T. Ito, K. Passerini, M. Sakamoto (2008) Structure Analysis of Keiretsu of Toyota, Encyclopedia of Networked and Virtual Organizations, pp.1542-1548, Idea Group Publishing 
4. T. Ito, C. Medlin, K. Passerini, M. Sakamoto (2009) Influence Trust and Trade in the Keiretsu of Toyota: A Centrality Analysis, Trust, Globalisation d Market Expansion, Chapter 8, pp.101-118, Nova Science

5. Ito T., Matsuno S., Xia Z., Sakamoto M., and Rajiv Mehta (2010) An Analysis of Interactive Influence in Mazda's Yokokai Keiretsu, Artificial Life and Robotics, Volume 15, Number 3, 249-252, Springer Japan

6. Ito T., S. Matsuno, R. Mehta, M. Sakamoto, S. Ikeda (2013), An analysis of inter-firms distances and corporate performance using DEC spatial model, Recent Advances in Energy \& Environment Integrated Systems, Proceedings of the 2nd International Conference on Integrated Systems and Management for Energy, Development, Environment and Health (ISMAEDEH '13), pp.80-85, April 23-25, 2013, Morioka City, Iwate, Japan

7. Ito T., S. Tagawa, R. Mehta, M. Sakamoto, S. Ikeda (2013), A research on inter-firms relationship using network-based DEA -A case study of Mazda Yokokai-, Recent Advances in Energy \& Environment Integrated Systems, Proceedings of the 2nd International Conference on Integrated Systems and Management for Energy, Development, Environment and Health (ISMAEDEH '13), pp.92-97, April 23-25, 2013, Morioka City, Iwate, Japan

8. Ito T., M. Hasama, R. Mehta, M. Sakamoto, S. Ikeda (2013), Measuring efficiency of firms in Yokokai using the IDCBI spatial model, Recent Advances in Energy \& Environment Integrated Systems, Proceedings of the 2nd International Conference on Integrated Systems and Management for Energy, Development, Environment and Health (ISMAEDEH '13), pp.116-122, April 23-25, 2013, Morioka City, Iwate, Japan

9. Ito T., Tagawa S., Matsuno S., Uchida Y., Sakamoto M., Ikeda S., Mehta R. (2013), An Analysis of Network Structure in Mazda's Yokokai using the DEC Spatial Model, Proceedings of the 2013 International Conference on Business Administration, Marketing, and Economics (MAME 2013), Recent Advances in Business Administration, Marketing and Economics, pp.77-81, September 28-30, 2013, Venice, Italy

10. JAPIA\&APPC (2005) Japanese Automotive Parts Industry, Automotive Parts Publishing Company, (Japanese Edition) 